\title{
OS DEVERES FUNDAMENTAIS E A DESOBEDIENCIA CIVIL EM DEMOCRACIAS DE BAIXÍSSIMA INTENSIDADE - APROXIMAÇÕES E DISTANCIAMENTOS A PARTIR DA ILEGITIMIDADE DE UM GOVERNO
}

Daury Cesar Fabriz ${ }^{1}$

Heleno Florindo da Silva ${ }^{2}$

\section{Resumo}

A realidade presente da política, sobretudo do modo de se fazê-la a partir da crise econômica mundial em 2008, trouxe países periféricos, bem como alguns centrais, para um debate interessante acerca dos desdobramentos do modelo (neo)liberal da democracia representativa (democracia de baixa/baixíssima intensidade), no tocante ao afastamento da sociedade civil frente a seus governantes, principalmente em contextos em que tal afastamento promove o surgimento de governos e representantes ilegítimos que buscam, em meio ao cenário conturbado, emplacar reformas estruturais em seus países, o que poderá, conforme será discutido neste estudo, ensejar, a partir da análise sobre o direito de resistência e seu processo de caracterização em desobediência civil, a possível existência de um dever fundamental de desobedecer civilmente as leis ou atos políticos emanados desses governos ilegítimos, frutos desses cenários conturbados de crise econômica, institucional e política.

Keywords: Fundamental Duties; Civil Disobedience; Democracy of Very Low Intensity; Illegitimacy; Government.

\footnotetext{
${ }^{1}$ Doutor em Direito pela Universidade Federal de Minas Gerais. Coordenador do Programa de Pós-Graduação Stritu Sensu em Direitos e Garantias Fundamentais (Mestrado e Doutorado) da Faculdade de Direito de Vitória. Coordenador do Grupo de Pesquisa Estado, Democracia Constitucional e Direitos Fundamentais. Presidente da Academia Brasileira de Direitos Humanos $(\mathrm{ABDH})$.Professor. E-mail: daury@terra.com.br.

${ }^{2}$ Membro do Grupo de Pesquisa Estado, Democracia e Direitos Fundamentais, do Programa de Pós-Graduação Stritu Sensuda Faculdade de Direito de Vitória (FDV). Doutorando em Direitos e Garantias Fundamentais pela Faculdade de Direito de Vitória (FDV). Membro da Diretoria Executiva da Academia Brasileira de Direitos Humanos (ABDH). Professor e Coordenador Geral do Curso de Direito da Faculdade Multivix (Cariacica/ES).E-mail: hfsilva16@hotmail.com.
} 


\section{INTRODUÇÃO}

O cenário político atual, seja em contextos sociais periféricos, como o latino-americano, seja na realidade dos países centrais do mundo que se globalizou (EUA e Europa), é de turbulência e de reavivamento de antigos "fantasmas", um cenário onde as instituições da política, construídas sobre os fundamentos democráticorepresentativos, voltam à cena principal, como locus deliberativo para a retomada do rumo depois da Tsunami que abalou as estruturas do mercado mundial, desde 2008.

Sendo a Política inerente a todos nós, os debates que passaram a fazer parte, nos últimos anos, do cotidiano das pessoas, vez ou outra, passam por assuntos envolvendo economia, política, justiça, entre outros temas, que reforçam a compreensão de que a partir de momentos de crise (econômica, política, institucional), voltamos nossa atenção ao cenário que aparentemente tínhamos nos afastado, qual seja, o das decisões políticas.

O ressurgimento de discussões e de instabilidade política numa sociedade (semi)periférica ${ }^{3}$, em desenvolvimento, extremamente desigual, como a brasileira deste início de século XXI, que poderia ser visto como algo positivo para todos, acabam trazendo, a cada dia mais para essa "arena política" que está em alta, "discursos conservadores", ou seja, "estamos vivendo em sociedades politicamente democráticas, mas socialmente fascistas" (SANTOS, 2016, p. 13).

E é a partir desse contexto de ressurgimento do debate político, da necessidade de enfrentarmos as crises que nos assombram, sejam elas de natureza econômica, institucional ou política, que o presente trabalho se mostra relevante para compreensão e discussão de temas que se desdobram desse cenário, tais como a questão da desobediência civil, dos deveres fundamentais e da democracia 5 .

A partir de então, num primeiro momento, o presente estudo buscará compreender o direito de resistência e como, a partir de seus fundamentos, é possível compreendermos o direito a desobediência civil como um desdobramento evolutivo daquele, a fim de que seja possível aproximarmos e distanciarmos entre si, a resistência e a desobediência civil, analisando, frente a última, suas principais características.

\footnotetext{
${ }^{3}$ Sobre tal constatação, importantes são as palavras de Santos (2016, p. 7), para quem “(...) os países semiperiféricos tendem a ser caracterizados por grande instabilidade política”. Ainda acerca desse aspecto das referidas sociedades, o mesmo Santos apontará que "as sociedades que foram colonizadas ainda hoje estão divididas entre dois grupos de populações: os que não podem esquecer e os que não querem lembrar. Os que não podem esquecer são aqueles que tiveram de construir como sua a pátria que começou a lhes ser imposta por estrangeiros; os que não querem lembrar são aqueles a quem a custa reconhecer que a pátria de todos tem, em suas raízes, uma injustiça histórica que está longe de ser eliminada e que é tarefa de todos eliminar gradualmente” (2016, p. 103).

${ }^{4}$ Segundo Santos, o "Fascismo Social" é um regime que constituirá o outro lado das democracias de baixa intensidade (2016, p. 21).

${ }^{5}$ A democracia será trabalhada neste estudo a partir de uma visão crítica de seu modelo representativo de corte liberal e, sobretudo, neoliberal, como forma de afastamento do povo, real titular do poder que fundamenta o Estado, das decisões políticas daqueles que governam esse Estado. Tal perspectiva será identificada a partir de Santos (2016) e Eley (2005), daquilo que chamam de democracia de baixa intensidade ou baixíssima intensidade.
} 
De outro lado, no segundo ponto do trabalho, buscaremos analisar os deveres fundamentais, buscando compreender seus principais fundamentos, bem como apresentar um conceito possível ao tema, a fim de que ao final, seja possível identificar a possibilidade de aproximação entre a desobediência civil e os deveres fundamentais.

Por fim, na terceira parte do trabalho, falaremos acerca daquilo que compreendemos, a partir do cenário posto, como democracias de baixíssima intensidade, a fim de buscar fundamentos para a compreensão da existência de um dever fundamental de desobedecer civilmente uma lei ou ato político de um governo, que neste contexto democrático representativo de baixíssima intensidade, é visto como ilegítimo.

Assim, em que pesem as discussões sobre as características inerentes aos deveres fundamentais, sobre a resistência ou a desobediência civil, bem como àquilo que aqui chamaremos de democracias de baixíssima intensidade, temas que serão trabalhados ao longo deste estudo, mesmo que de forma breve em decorrência das características do mesmo, o importante é saber que por se tratar de campos que ainda estão em desbravamento, no caso dos deveres fundamentais, ou que, mesmo antigos, ainda são construídos abertamente, a partir de concepções teórico-conceituais distintas, no caso da desobediência civil e da democracia representativa (baixa intensidade), ficará clara aqui a inexistência de uma busca por verdades absolutas.

Não havendo tal contexto de unicidade do pensamento científico-filosófico sobre os temas discutidos neste trabalho, mas, pelo contrário, havendo inúmeras possibilidades, tal fato irá corroborar, conforme destacado abaixo, a necessidade do desenvolvimento do presente estudo a partir de uma perspectiva metodológica ínsita ao paradigma filosófico do múltiplo-dialético ${ }^{6}$.

Diante disso, o presente estudo buscará fundamentos, a partir de um movimento dialético, conforme destacado acima, à resposta do presente problema de pesquisa: em um contexto de democracia de baixíssima intensidade na qual inúmeros países, sobretudo o Brasil, estão inseridos nos últimos anos, fruto de um distanciamento entre a política enquanto local de realização do poder e tomada de decisões e a sociedade civil (povo) detentora real desse poder, é possível identificarmos a existência de um dever fundamental à prática da desobediência civil frente aos atos político-normativos que forem praticados por um governo - seja pela

\footnotetext{
${ }^{6} \mathrm{O}$ paradigma múltiplo-dialético pode ser compreendido desde sua matriz grega, até a contemporaneidade, como o modelo de racionalidade capaz de possibilitar a existência de inúmeras realidades que, mesmo sendo diferentes entre si, convivem em harmonia dentro de uma mesma realidade político-social, ou seja, é o que nos possibilitará perceber a multiplicidade de existência e de modos de compreensão possíveis, bem como a compreensão de que está tudo inter-relacionado, de que tudo o que existe está ligado a ponto de ser especial para a vida em harmonia. É neste sentido que Krohling apontará para o fato de que desde sua formação mais incipiente, na Grécia antiga, a perspectiva do múltiplo-dialético ser um importante marco na ascensão e promoção do debate sobre quaisquer situações, o que possibilitará, não só o surgimento, mas a necessidade de sua realização prática, do que hoje chamamos de diferença ou, mais recentemente, de diversidade, pois segundo ele "Os gregos já tinham saído da mitologia, pois viviam a presença de um novo marco, isto é, a realidade da pólis, que modificou profundamente a sua maneira de ser e viver. (...) a ágora (praça pública) é o principal espaço e instrumento de poder. Nesse cenário descendências monárquicas, origens divinas da natureza e explicações mitológicas do poder não têm mais guarida. (...) tudo é debatido. As pessoas agora são iguais. Não há mais
} 
impopularidade ou pelo contexto de seu exercício democrático de baixíssima intensidade - reconhecido como ilegítimo?

\section{DO DIREITO DE RESISTÊNCIA A DESOBEDIÊNCIA CIVIL - UMA ANÁLISE CONCEITUAL E DISTINTIVA}

Para lançarmos as premissas através das quais compreendemos o direito de resistência e sua relação com o direito (dever) de desobediência civil, é necessário já fixarmos a compreensão de que se trata de uma relação entre um gênero e uma espécie, onde a desobediência civil poderia ser percebida como um desdobramento específico, do direito de resistência que lhe antecede.

A relação, a partir desses fundamentos, entre a resistência e a desobediência civil, será compreendida como simbiótica, pois não há como compreendermos a existência de um direito a desobediência civil - ou como se debaterá abaixo, a possibilidade até mesmo percebê-la a partir da perspectiva teórico-filosófica dos deveres fundamentais - sem, primeiro, fixarmos o direito de resistência e, mesmo que brevemente, pois esse não é o objetivo do presente trabalho, o distanciarmos ou aproximarmos do exercício da desobediência civil como seu desdobramento.

Em uma obra que percorrerá historicamente o trajeto pelo qual o direito de resistência fora discutido desde a antiguidade, Paupério (1997) analisará o direito de resistência desde o Código de Hamurabi, que a mais de dois mil anos já identificava o direito de rebelião contra o governante que violasse o mandamento das leis, passando por Sófocles em Antígona, por onde há uma discussão acerca do desrespeito a uma dada lei do Rei Creonte que impediria Antígona de sepultar seu irmão Polinicer, até mesmo, por exemplo, com a ascensão da religião cristã como base racional do Império Romano Ocidental, identificar uma condenação ao direito de resistir à autoridade governamental, conforme a necessidade de obedecer, totalmente, a qualquer governante, o que se vê na Epístola de Paulo aos Romanos ${ }^{8}$.

Durante os séculos de ascensão do Estado de Direito, constitucionalizado, fruto das grandes revoluções que marcaram os sécs. XVII e XVIII identificou-se também o direito de resistência, por exemplo, na figura do tiranicídio, ou seja, uma faculdade dada ao povo de matar o governante tirânico que estivesse exercendo maléfica e

hierarquia absoluta e muito menos monarquia. (...). Esse é o marco inicial. Não há nada que não possa ser discutido. Não existem mais verdades eternas (2014, p. 23-24).”

${ }^{7}$ Em destaque personagens da referida peça grega Antígona de Sófocles.

${ }^{8}$ É importante destacarmos nesse contexto de verificação histórica do direito de resistência, a compreensão de Costa (1990, p. 3), para quem a resistência estaria fundamentada, primordialmente, em dois institutos da Idade Média, quais sejam: a commendatio o dever de fidelidade entre os vassalos e seus senhores - e o beneficium - uma determinação para que todos os soberanos se orientassem pelos fundamentos do cristianismo, sob pena de justificar atos de desobediência. 
ilegitimamente o poder do povo constitutivo do Estado (PAUPÉRIO, 1997, p. 120-152).

Portanto, sejam quais forem as bases históricas para a justificação do direito de resistência, é inegável que o mesmo se trata de uma possibilidade que, mesmo não estando, porventura, presente em um dado ordenamento jurídico", não pode ser por ele proibido, pois conforme Lafer nos chama a atenção para o fato de que "se o legislador pode reivindicar o direito de ser obedecido, o cidadão pode igualmente reivindicar o direito a ser governado sabiamente e por leis justas (1988, p. 188)".

Tais premissas nos ajuda a reforçar a compreensão de que o poder emanado do povo, poderá ser efetivado a fim de lhe realizar, tão somente, o bem comum, ou seja, sempre que o exercício do poder por parte dos agentes do governo do Estado, não for concretizado a partir dessa perspectiva é necessário que se reconheça o direito desses cidadãos, que se encontram afastados do referido exercício do poder do Estado, de não o reconhecer como legítimo, sendo assim, o direito de resistir a tal poder, pois segundo La Boétie

No momento gostaria apenas que me fizessem compreender como é possível que tantos homens, tantas cidades, tantas nações às vezes suportem tudo de um Tirano só, que tem apenas o poderio que lhe dão, que não o poder de prejudicá-los senão enquanto aceitam suportá-lo, e que não poderia fazer mal algum se não preferissem, a contradizê-lo, suportar tudo dele (2003, p. 25-26)

Contudo, o império do direito produzido pelo Estado constitucionalizado liberal dos séculos XVIII e seguintes, produziu, sobretudo a partir de seus fundamentos contratualistas ${ }^{10}$, um movimento de restrição ao direito de resistência, tendo em vista que se passou a compreender o dever legal de obediência ao ordenamento jurídico ${ }^{11}$ como um dos fundamentos mais elementares do Estado de Direito, bem como que tal ordenamento, institucionalizado em forma de um Estado legalizado, seria capaz de impedir os arroubos tirânicos de quaisquer governantes que se ascendessem ao governo do Estado.

A legalidade passou a ser, portanto, sinônimo da legitimidade de uma legislação ou dos atos de um

\footnotetext{
${ }^{9}$ Neste ponto, apontado ordenamentos que reconheciam o direito de resistência expressamente, Lafer destaca que a própria declaração de independência dos EUA de 1776 reconhece o direito e o dever de resistir ao povo americano, sempre que for necessário "alterar, abolir ou instituir um novo governo se ocorrerem abusos ou usurpações despóticas" (1988, p. 190). No mesmo contexto, a Declaração de Virgínia, em seu art. 3º, determina a possibilidade, sempre que o governo não proporcionar segurança e proteção ao povo, de se abolir tal governo, ou seja, um "direito inalienável de reformá-lo, alterá-lo ou aboli-lo de maneira considerada condizente com bem público” (LAFER, 1988, p. 191). Por fim, a Declaração dos Direitos do Homem e do Cidadão de 1789 , em seu art. $2^{\circ}$, reconhecia o direito de resistência ao determinar que "a finalidade de toda associação é a conservação dos direitos naturais e imprescritíveis do homem; esses direitos são a liberdade, a segurança e a resistência à opressão”.

${ }^{10}$ Sobre essa perspectiva, Lucas nos chama atenção para o fato de que no contratualismo "a sociedade civil, vista sob este ângulo, encontra seu princípio de legitimação exclusivamente no consenso. (...). A razão pela qual as pessoas abandonam a liberdade natural e se refugiam na sociedade civil consiste em compartilhar com todas as outras pessoas o desejo de unirem-se para manterem um estado de segurança, e que conserve o direito natural de propriedade que possuem. Tem-se assim, que o consentimento dá legitimidade ao governo e gera um grau de reciprocidade entre este e o povo, resultando deste ex contractu o dever de obediência" (1999, p. 29).

${ }^{11}$ Aqui as palavras de Lucas (1997, p. 33) são elucidativas, uma vez que ele destaca que neste contexto a “(...) lei se apresenta como a racionalização dos objetivos da sociedade e como mecanismo capaz de limitar de maneira eficaz os abusos do poder, razão pela qual o dever de obediência como forma de legitimação passou a dominar o mundo moderno”.
} 
governante, de modo que essa confusão entre a legitimidade dos atos governamentais e sua legalidade, não houve mais condições do cidadão se contrapor a lei, haja vista que a legalidade, o Estado de Direito, substituto do modelo absolutista, passou a representar o paradigma a ser alcançado pela modernidade no desenvolvimento do Estado constitucional.

A partir de então, a representação democrática como fonte de exercício do poder do povo pelos governantes do Estado de Direito, fez com que a vontade externada pela maioria (o que, em um primeiro momento, se deu de forma censitária, ou seja, uma "maioria" não em termos numéricos, mas tem termos econômicos) fosse a vontade do povo e, consequentemente, a vontade do Estado ${ }^{12}$.

Contudo, essa construção democrática do ordenamento através do exercício da democracia representativa (maioria popular), não retirará, por si só, a possibilidade da do surgimento de uma legislação opressiva, o que, ocorrendo, fará emergir de tal contexto, um dever ético do cidadão em transgredir o ordenamento opressor, principalmente, pelo fato de que lembra Thoreau "a lei jamais tornou os homens mais justos, e, por meio de seu respeito por ela, mesmo os mais bem-intencionados transformaram-se diariamente em agentes da injustiça”" (1999, p.9).

Assim, a partir dessas perspectivas conceituais acerca do direito a resistência, é que será possível compreendermos seu processo evolutivo para a encarnação daquilo que aqui se discutirá como desobediência civil, ou seja, como instrumento de combate a opressão e as injustiças político-normativas, perpetradas, sobretudo, por agentes políticos ilegítimos ${ }^{13}$, bem como, nos termos lançados por Cohen e Arato, “(...) meio de reforçar o vínculo entre a sociedade civil e a sociedade política" (1997, p. 588).

Com relação a desobediência civil, a partir de então, é importante destacarmos uma série de características que, segundo a doutrina especializada sobre o tema, podem compor um sentido teórico-filosófico para seu exercício, quais sejam, se tratar a desobediência civil de um ato político; coletivo e público; contrário a lei e não violento, cujo objetivo é a realização de uma modificação no ordenamento jurídico ou nas práticas e atos de um governo.

Neste sentido, Rawls (2008, p. 274) destaca que "como um ato político, não violento, consciente e, apesar disto, político contrário à lei, praticado com o intuito de promover uma modificação na lei ou práticas do

\footnotetext{
${ }^{12}$ Thoreau identificará a força da maioria em realizar o governo do Estado, chegando as seguintes conclusões "a razão prática por que se permite que uma maioria governe, e continue a fazê-lo por um longo tempo, quando o poder finalmente se coloca nas mãos do povo, não é a de que esta maioria esteja provavelmente mais certa, nem a de que isto pareça mais justo para a minoria, mas sim a de que a maioria é fisicamente mais forte" (1999, p. 8).

${ }^{13}$ Repolês identifica uma distinção básica entre o direito de resistência e a desobediência civil no seguinte sentido "a desobediência civil se apoia em bases constitucionais e, por isso mesmo, enquanto fenômeno específico, não se confunde com o direito de resistência, que, ao contrário, questiona a própria autoridade do governo como governo legitimamente instituído” (2003, p. 19-20).
} 
governo ${ }^{14 "}$

A partir de então, a desobediência civil é um ato político por ser realizado tendo como perspectiva princípios políticos da vida em comunidade, princípios esses, inerentes a compreensão de justiça que fundamentam a Constituição e todas as instituições de um Estado Democrático de Direito (LUCAS, 1999, p. 39).

Ou seja, a desobediência civil pode ser compreendida como a última ou o único meio de realização das vontades populares, de expressão do que um determinado grupo social quer ou busca realizar, que deverá sempre ser realizada, quando todas as soluções reconhecidamente instituídas pelo ordenamento jurídico de um país, se mostrarem ineficazes para tal contexto, ou quando, as instituições usarem desse ordenamento e de sua estrutura, como justificativa legal de exercício ilegítimo de um poder, cujo titular máximo é o povo (MARASCHIN e BRUSCATO, 2011, p. 56-57).

Sempre que tal situação ocorrer, será por meio da desobediência civil que se buscará, portanto, a inserção no espaço público, sendo essa a forma encontrada - diante da ineficácia das soluções institucionais ou de seu mal uso - para que o povo possa participar verdadeiramente da vida em sociedade, do exercício pelo da cidadania, da tomada de decisões que poderão impactar, não somente as gerações presentes, mas, sobretudo, as futuras gerações de um dado país, tal e qual vem ocorrendo, por exemplo, no Brasil nos últimos anos.

De outro lado, a desobediência civil pode ser compreendida como um ato coletivo ${ }^{15}$, ou seja, há que existir no contexto desobediente um número significativo de indivíduos, sobre pena do ato configurar, mais o exercício de resistência individuais do que propriamente de uma desobediência civil.

Sendo assim, Arendt (1988) chega à conclusão de ser a desobediência civil uma ação de grupo, pois para ela, não seria a desobediência civil uma atitude fundamentada na consciência individual do ser, mas, ao contrário, seu fundamento maior estará numa consciência coletiva, política e social acerca do fenômeno que precederá a deflagração do ato desobediente.

Além do caráter, portanto, da coletividade do ato desobediente, existe a necessidade que esse ato não se dê de forma "escondida", ou seja, que a desobediência civil ocorra publicamente, que seja uma atitude a conclamar

\footnotetext{
${ }^{14}$ Acerca de tal constatação, importantes são as palavras de Michael Walzer (1997, p. 26), que aponta para a desobediência civil como sendo um conflito de caráter não-revolucionário em face do Estado, ou seja, mesmo que uma pessoa ou um grupo de indivíduos, infrinjam o ordenamento jurídico de um país, por sentirem-se moralmente obrigados a tanto, tal violação não minimiza ou desconhece a necessária existência dos sistemas legal ou político de um país, tendo em vista que reconhecem o valor moral do Estado (1997, p. 26)

${ }^{15}$ Sobre tal característica é importante destacar que não há unanimidade da doutrina especializada sobre o tema acerca do caráter coletivo do ato de desobediência civil, pois existem autores que a identificam na conduta individual ou de um número reduzido de pessoas. Para uma melhor compreensão sobre tal perspectiva, impossibilitada neste estudo, em decorrência da limitação de seu tamanho e problemática, ver THOREAU, Henry David. A desobediência civil. Tradução: Sérgio Karam. Porto Alegre: L\&PM,
} 
mais adeptos ao ato, de forma que será através de sua publicidade que será possível identificar o sentido político e coletivo do ato desobediente.

Sobre a publicidade do ato desobediente, importantes são as palavras de MARASCHIN e BRUSCATO, 2011,p. 58), para quem

Sendo instrumento de persuasão, a desobediência civil é dirigida à sociedade, extraindo a sua razão de ser como mecanismo exercido perante a esfera pública, no âmbito da "praça pública". Assume, assim, uma função pública informadora da sociedade, questionando-a, todavia. O seu caráter público surge a partir dos objetivos dos desobedientes, ou seja, mais do que exteriorizar as suas demandas, influenciando a tomada de decisões, os desobedientes pautam as suas ações em interesses coletivos e não em valores individuais ou particulares.

Portanto, é importante concluir neste ponto, que a ideia inerente ao caráter de ser um ato público, não está restringida ao simples fato de ser sido desencadeada em um local público, mas, especificamente, por ser a desobediência civil um ato dirigido, também, por princípios públicos, ou seja, um ato que é abertamente praticado, com uma clara e verdadeira comunicação à sociedade no qual o mesmo emerge, não sendo algo encoberto, secreto ou, até mesmo, velado (RAWLS, 2008, p. 405).

De outro lado, acerca do fato de a desobediência civil ser uma atitude contrária a lei, ilegal, ou simplesmente o exercício de um direito reconhecido constitucionalmente ${ }^{16}$, seja expressa ou implicitamente, importante se faz ressaltar alguns pontos, a começar por Garcia (2004, p. 240-326), que identifica a desobediência civil como sendo um direito fundamental de garantia, que estaria contido constitucionalmente na Constituição Federal de 1988 (CF/88) em no dispositivo contido no 5º parágrafo 2º, ou seja, numa espécie de cláusula constitucional de abertura a outros direitos fundamentais que não somente aqueles reconhecidamente de forma expressa no Texto Constitucional.

Assim, para citada autora, a desobediência civil decorreria de um direito fundamental à liberdade, de modo que estaria destinado, entre outros pontos, à proteção da cidadania, identificada como o ponto mais alto do referido direito à liberdade. Estaria a desobediência civil neste contexto, sendo um ato legal, pois se trataria do um exercício de um direito constitucionalmente reconhecido.

Contudo, de um modo diferente, Cohen e Arato (1997, p. 29-82), destacam que a existência de uma discussão acerca da existência ou não de qualquer fundamento legal para, não só o exercício, mas a existência do

1997. Para Thoreau, está no indivíduo ou em grupos mais reduzidos de pessoas, a realização mais produtiva e significativa dos atos de desobediência.

${ }^{16}$ Neste ponto em que se discute a desobediência civil como ato contrário a legislação ou como mero exercício de um direito reconhecido expressa ou implicitamente pelo ordenamento jurídico, que lhe precede ou dele decorre, importantes são as palavras de Rawls (2008, p. 404), para quem "às vezes há fortes razões para não se infringir a lei ou a política tida como injusta. Em vez disso, alguém pode desobedecer a leis de trânsito ou entrar ilegalmente numa propriedade como uma forma de apresentar os seus argumentos. Assim, se o governo estabelecesse uma lei vaga e rígida contra a traição, não seria apropriado cometer uma traição como uma maneira de lhe fazer objeção, e de qualquer modo a pena poderia ser muito maior do que alguém estaria razoavelmente disposto a aceitar". 
direito a desobediência civil, pode ser compreendida como uma contradição em si mesma, pois o ato desobediente é, por sua própria natureza, um ato que afronta o ordenamento jurídico, por identificar em uma norma ou ato de um governo, uma injustiça ou ilegitimidade.

Sendo assim, reduzir o contexto do exercício da desobediência ao seu reconhecimento como direito, é impossibilitá-lo de ser realizado, de modo que para eles, acarretando na impossibilidade de sua institucionalização.

Desse modo, seja como identificamos a desobediência civil, o importante é analisar seu caráter de contrariedade com o que o ordenamento jurídico passa a compor, através de legislações que surgem ou atos políticos que são tomados no desenrolar de um dado governo.

Por fim, a desobediência civil trata-se de um ato não violento cujo objetivo, conforme destacado acima, é a realização de uma modificação no ordenamento jurídico ou nas práticas e atos de um governo, por considera-las injustas, ilegítimas, contrárias àquilo que seria o melhor para o povo ${ }^{17}$.

Neste ponto, Ralws (2008, p. 405-406), debatendo o caráter de não violência ${ }^{18}$ dos atos de desobediência civil, destacará que em tal contexto deverá se buscar evitar as práticas violentas em face das pessoas, ou seja, na prática da desobediência civil

Procura evitar o uso da violência, especialmente contra as pessoas, não por abominar o uso da força por princípios, mas por ser uma expressão conclusiva do argumento de alguém. Envolver-se em atos violentos que tendem a prejudicar e a ferir é incompatível com a desobediência civil entendida como uma forma de apelo público. De fato, qualquer interferência nas liberdades civis dos outros tende a retirar do ato de um cidadão a qualidade de desobediência civil.

A desobediência civil, portanto, que surge como instrumento de contraposição às leis ou atos políticos de um dado governo, se constitui em mecanismo inerente ao exercício da cidadania, cujo objetivo principal deve ser a busca por alterar, de forma pacífica as práticas governamentais ou sua legislação que acaba de ser criada (COSTA, 1990, p. 35), ou seja, “(...) persuadir a opinião pública na sociedade civil e na política (ou na sociedade econômica) de que uma lei ou política específica é ilegítima e de que uma mudança é justificada ${ }^{19}$ " (COHEN e ARATO, 1997,

\footnotetext{
${ }^{17}$ Sobre tais pontos, é importante destacar que a desobediência civil "objetiva modificar as práticas e leis injustas sem jamais se colocar contra a ordem jurídica como um todo. Não põem à prova a legitimidade do sistema, mas sim daquelas normas e práticas injustas" (LUCAS, 1999, p. 40).

${ }^{18} \mathrm{O}$ reconhecimento da desobediência civil a partir dessa característica acerca da inexistência total de violência em atos desobedientes pode ser, no mínimo, questionável, tendo em vista que alguma violência sempre será passível de ser observável nos atos de desobediência sem que isso retire dessa contrariedade, seu caráter desobediente. É o que nos chama atenção Walzer (1997, p. 26-27) "A insistência na não-violência total é enganosa porque, em primeiro lugar, ignora o poderoso efeito que a desobediência frequentemente tem sobre observadores inocentes, em segundo lugar, ignora a violência real que a desobediência provoca (e que às vezes pretende provocar), especialmente da parte da polícia”. De outro lado, segundo Costa (1990, p. 37) personagens como Mohandas Karamachad Gandhi e Martin Luther King, assim como descrito acima por Rawls, reconheciam a prática da desobediência civil como algo eminentemente não violento, ou seja, "ela deveria ser aberta, e acima de tudo, ser levada a cabo por grandes massas e completamente sem violência".

${ }^{19}$ No original: "The aim of civil disobedience is to persude public opinion in civil and political society (or economic society) that a particular law or policy is illegitimate and a change is warranted."
} 
p. 587 - tradução nossa)

Por fim, vistas as características que a doutrina especializada identifica aos atos de desobediência civil, bem como o fato de ser a desobediência civil ser um desdobramento do direito de resistência, nos próximos tópicos desse estudo, iremos trabalhar os deveres fundamentais e como esses podem se aproximar da prática da desobediência civil, a fim de que ao final, seja possível extrairmos a existência de um dever fundamental de desobedecer leis ou atos políticos de um governo reconhecidamente ilegítimo.

\section{OS DEVERES FUNDAMENTAIS ${ }^{20}$ E A SUA APROXIMAÇÃO A PRÁTICA DA DESOBEDIÊNCIA CIVIL}

O estudo dos deveres fundamentais não é tarefa fácil, seja pelo fato do constitucionalismo moderno ocidental sempre buscar enaltecer os direitos que são regulamentados nos Textos Constitucionais do Estado de Direito, seja em decorrência dos poucos estudos sobre o tema ${ }^{21}$, em que pese sua real importância social, política e cultural.

É a partir desse cenário que o presente trabalho abordará aspectos gerais acerca de uma teoria dos deveres fundamentais, buscando contribuir para o desenvolvimento de um maior entendimento acerca dos deveres fundamentais, sobretudo, como discutido acima, sobre os deveres e sua aproximação das discussões acerca da desobediência civil em democracias de baixíssima intensidade, sempre que neste contexto houver propostas para reformas estruturais nos direitos fundamentais reconhecidos, constitucionalmente pelo Estado, a partir da ascensão de governos ilegitimos ${ }^{22}$.

\footnotetext{
${ }^{20}$ A construção teórica acerca dos deveres fundamentais realizada neste ponto do trabalho, já fora realizada por nós em outro trabalho, sendo realizadas, neste sentido, quando necessário, modificações de alguns de seus desdobramentos fundamentais na busca de sua adequação ao problema de pesquisa destacado acima. Para verificação dos referidos trabalhos, ver SILVA, Heleno Florindo da e FABRIZ, Daury Cesar. O MEIO AMBIENTE NATURAL E A PROTEÇÃO INTEGRAL DAS CRIANÇAS: a Educação Ambiental como Dever Fundamental dos Pais para a Preservação das Presente e Futuras Gerações. In.: Revista do Programa de Pós-Graduação em Direito da UFC. Vol. 35, n. 2, 2015, p. 181-200.

${ }^{21}$ Um importante local de estudos dos Deveres Fundamentais no Brasil, é o Grupo de Pesquisa Estado, Democracia e Direitos Fundamentais, do Programa de Pós Graduação Stritu Sensu da Faculdade de Direito de Vitória, que a quase uma década, de forma pioneira e corajosa, vem estudando o tema dos Deveres Fundamentais a partir de vários prismas diferentes, desde uma teoria geral do deveres fundamentais, bem como os problemas acerca dos vários tipos de meio ambiente, dos desdobramentos da nova legislação processual civil brasileira de 2015, até a atual abordagem acerca da desobediência civil e a possibilidade de sua aproximação com os debates acerca dos deveres fundamentais.

${ }^{22}$ A ilegitimidade de que trata o presente trabalho, dentre outros fundamentos, que desde o seu início, já vem sendo construído, também para pelo reconhecimento, no exemplo do caso brasileiro atual, por pesquisas populares acerca da aprovação de um dado governo. A título, meramente exemplificativo, o atual governo brasileiro nas pesquisas de setembro e outubro, realizadas pelos Institutos Ibope e Datafolha, aparece, respectivamente, com 3\% e 5\% de aprovação popular. Assim, não só pelas referidas pesquisas, mas também por elas, o caso brasileiro é exemplo mais do que claro, de um contexto de falta de legitimidade de um governo para implementação de reformas estruturais em um país, sobretudo no contexto brasileiro de - ainda - profunda desigualdade social. As
} 
Assim, ao analisarmos as construções teóricas acerca dos deveres fundamentais - ou constitucionais inerentes a um determinado ordenamento jurídico constitucional, percebemos que alguns autores apontam, de um lado, a falta de efeitos jurídicos desses deveres fundamentais constitucionais e, de outro, que tais deveres representariam uma forma de limitação aos limites materiais do poder público.

Neste sentido, aponta Llorente (2001, p. 16) que:

Os enunciados de deveres não têm efeitos jurídicos algum, mas apenas, e se houver, uma função política, embora tampouco haja unanimidade em discernir qual função, se existir alguma, esses enunciados desempenham: para uns, tem, simplesmente, a função de servir de sustento ideológico ao poder, na tentativa de lhe dar uma fundamentação ética; para outros, ao contrário, a função dos deveres, tal como a dos direitos, é a de impor limites materiais a potestade normativa do poder público ${ }^{23}$.

É possível visualizar, a partir de então, que as discussões acerca da configuração jurídica dos deveres fundamentais é campo arenoso, por onde se debruçam incansáveis teorias na tentativa de lhes dar normatividade ou, simplesmente, lhes reconhecer como meros deveres éticos das pessoas enquanto pertencentes ao grupo social que conforma o Estado.

De outro lado, é importante destacar também, não como são simples divagações ou elucubrações teóricas, mas ao contrário, como importantes contribuições para o desenvolvimento do tema, aquelas vertentes que não percebem nos deveres fundamentais um caráter normativo, mas, tão somente, um dever ético, haja vista o fato de que em suas origens, os deveres fundamentais ou constitucionais, terem surgido de discussões de cunho religioso, moral ou filosófico (PECES-BARBA MARTÍNEZ, 1986, p. 329).

A fim de fixar as características que nos permitarão identificar os deveres fundamentais, destacamos as palavras de Peces-Barba Martínez (1986, p. 335), para quem esses deveres fundamentais apresentam três aspectos principais, que podem ser elencados da seguinte forma

(...) a) o dever jurídico existe com independência de que o dever trabalhado tenha tido previamente, ou não, uma dimensão moral (...); b) o dever jurídico tem que estar reconhecido por uma norma pertencente ao Ordenamento; c) normalmente os deveres jurídicos trazem consigo uma sanção para os casos onde houver o seu inadimplemento $(\ldots)^{24}$.

Em que pese a logicidade e a tenacidade dos citados argumentos, outros existem, tão robustos quanto, que disciplinam os deveres fundamentais sob uma visão diferente, de modo que, por exemplo, argumentos que

referidas pesquisas estão disponíveis, respectivamente, em: <https://www.cartacapital.com.br/politica/com-3-temer-tem-a-pioraprovacao-desde-o-fim-da-ditadura $>$ e $<$ http:// datafolha.folha.uol.com.br/>.

${ }^{23}$ No original: "Los enunciados de deberes no tienen efectos jurídico alguno, sino sólo, si acaso, una función política, aunque tampoco hay unanimidad a la hora de discernir cual sea (si alguna), la que estas normas desempeñan: para unos, simplemente la de servir de sustento ideológico al poder, la de intentar dotarlo de una fundamentación ética; para otros, más bien al contrario, la función de los deberes, como la de los derechos, es la de imponer limites materiales a la potestad normativa del poder público" (Tradução nossa). 
identificam os deveres fundamentais compreendidos, assim como os direitos fundamentais, não só a partir de sua presença expressa no Texto Constitucional.

Há quem entenda que esses deveres, mesmo que não presentes expressamente em um determinado ordenamento poderão ser reconhecidos como tal, a partir, por exemplo, de uma leitura ampla da norma que regula um determinado direito que, para ser exercitado, necessitará que alguém cumpra um determinado dever.

É o que Valdés (1986b, p. 68), em resposta às críticas de Francisco Laporta e Juan Carlos Bayón, feitas a um artigo que aquele havia publicado acerca dos deveres positivos gerais e sua fundamentação, ressaltará, no sentido de que, para a imposição desses deveres, de um ponto de vista meramente ético, não é necessária a existência do Estado.

Sendo assim, para Valdés os deveres fundamentais existem, independentemente, da existência de uma codificação estatal sobre sua fundamentação, pois o Estado servirá, tão somente, para assegurar o cumprimento ou sancionar o não cumprimento desses deveres que são inerentes à sociedade humana.

Os deveres fundamentais ou constitucionais, portanto, conforme se depreende das análises teóricas acima, existem em decorrência de um direito fundamental que lhe será contrário, ou seja, na medida em que a Constituição, base do Estado de Direito, nos assegura uma série de direitos fundamentais, em contrapartida, faz surgir uma série de deveres que, também fundamentais, surgem como mecanismos para a possível concretização daqueles.

Tal construção hermenêutica é o que pode ser percebido da leitura, por exemplo, do artigo 75, da Constituição da República Dominicana de 26 de janeiro de 2010²5, responsável por trazer um rol de deveres

\footnotetext{
${ }^{24}$ No original: “(...) a) El deber jurídico existe com independencia de que el deber de que se trata hay a tenido previamente o no una dimensión moral (...); b) El deber jurídico tiene que estar reconocido por una norma perteneciente ao Ordenamiento; c) normalmente los deberes jurídicos llevan a pareja da una sanción en caso de incumplimiento (...)" (Tradução nossa).

${ }^{25}$ O citado artigo dispõe que: "CAPÍTULO IV - DE LOS DEBERES FUNDAMENTALES - Artículo 75 - Deberes fundamentales. Los derechos fundamentales reconocidos en esta Constitución determinan La existencia de un orden de responsabilidad jurídica y moral, que obliga La conducta del hombre y La mujer en sociedad. En consecuencia, se declaran como deberes fundamentales de las personas los siguientes: 1) Acatar y cumplir la Constitución y las leyes, respetar y obedecer las autoridades establecidas por ellas; 2) Votar, siempre que se este em capacidad legal para hacerlo; 3) Prestar los servicios civiles y militares que la Patria requiera para su defensa y conservación, de conformidad com lo establecido por la ley; 4) Prestar servicios para el desarrollo, exigible a los dominicanos y dominicanas de edades comprendidas entre los dieciséis y veintiún años. Estos servicios podrán ser prestados voluntariamente por los mayores de veintiún años. La ley reglamentará estos servicios; 5) Abstener se de realizar todo acto perjudicial a la estabilidad, independencia o soberanía de la República Dominicana; 6) Tributar, de acuerdo con la ley y en proporción a su capacidad contributiva, para financiar los gastos e inversiones públicas. Es deber fundamental del Estado garantizar La racionalidad del gasto público y La promoción de una administración pública eficiente; 7) Dedicar se a um trabajo digno, de suelección, a fin de proveer el sustento propio y el de su familia para alcanzar El perfeccionamiento de su personalidad y contribuir al bien estar y progreso de La sociedad; 8) Asistir a los establecimientos educativos de la Nación para recibir, conforme lo dispone esta Constitución, La educación obligatoria; 9) Cooperar con el Estado encuanto a La asistencia y seguridad social, de acuerdo con sus posibilidades; 10) Actuar conforme al principio de solidaridad social, respondiendo com acciones humanitarias ante situaciones de calamidad pública o que pongan en peligro la vida o La salud de las personas; 11) Desarrollar y difundir la cultura dominicana y proteger los recursos naturales del país, garantizando La conservación de un
} 
fundamentais para os dominicanos, que passam a ter uma Constituição que não está, tão somente, repleta de direitos, mas, também, de deveres.

Contudo, antes de continuar e aprofundar a discussão que fundamenta o presente trabalho, é necessário destacar, acerca dos deveres fundamentais, alguns pontos relevantes, tanto em relação às discussões acercada existência, ou não, de deveres positivos gerais, quanto, no caso de haver essa possibilidade, sobre o modo como se daria a contraprestação ao direito, pois todo dever, consequentemente, deverá encampar um direito que lhe é oposto.

Neste ponto, Valdés (1986a, p. 17) qualifica quais seriam esses deveres fundamentais de natureza geral, ou seja, aqueles que todos nós estaríamos obrigados a cumprir, independentemente de mantermos relação direta com aquele que possui o direito de lhe cobrar, expondo, neste sentido, que

Deveres positivos gerais são aqueles cujo conteúdo é uma ação de assistência ao próximo que requer um sacrifício trivial e cuja existência não depende da identidade do obrigado nem a do(s) destinatário(s) e tampouco é o resultado de algum tipo de relação contratual prévia $^{26}$.

Com isso podemos perceber que por este entendimento quaisquer pessoas poderiam, em estado de necessidade, obrigar quaisquer outros, a lhes ajudar, não devendo essa ajuda ser maior que algo trivial, ou seja, algo que não imponha àquele que presta a ajuda, uma diminuição de suas posses capaz de levá-lo ao status daquele a quem ajuda (VALDÉS, 1986a, p. 25).

Entretanto, existem posições diversas a essa, principalmente no tocante a possibilidade, ou não, da construção de um entendimento acerca dos deveres fundamentais, reconhecendo-os como positivos e gerais, conforme se depreende em Laporta (1986) e Bayón (1986) - ambos criticam, conforme destacado acima, as noções trazidas por Valdés (1986a) no tocante às mencionadas discussões.

Laporta (1986, p. 55) apresenta suas divergências à Valdés, em relação àquilo que esse chama de deveres positivos gerais, no ponto acerca da responsabilidade pela omissão, ou seja, Laporta traz entendimento de que se levarmos às propostas de Valdés às últimas consequências, as regras acerca da responsabilidade em decorrência de um inadimplemento de uma obrigação restariam inócuas.

Ele chega a essa conclusão, tendo em vista que sendo os deveres gerais, àqueles que tivessem, em contrapartida, direitos, poderiam escolher, dentre um universo de obrigados, àquele que the aprouvesse, o que retiraria toda e qualquer segurança jurídica dos processos judiciais, sendo que, aquele que tem direito frente a um coletivo de pessoas, frente a outras, possui o mesmo dever.

ambiente limpio y sano; 12) Velar por El fortalecimiento y La calidad de la democracia, El respeto Del patrimonio público y El ejercicio transparente de La función pública”. 
De outro lado, Bayón (1986) aponta críticas à postura de Valdés no tocante aos limites impostos a esses deveres positivos gerais que todos teríamos, destacando, especificamente, o critério da trivialidade entabulado por Valdés para limitar as obrigações, ou seja, os deveres dos indivíduos para com aqueles que lhes são comuns em uma sociedade.

Bayón (1986, p. 46) destacará, neste sentido, que “(...) o altruísmo mínimo, baseado na ideia de sacrifício trivial, parece que não nos serve (...). se alguém tem em seu poder recursos em abundância - sendo que frente a esses um terceiro tem direito - deve entregá-los em sua totalidade, não uma parte $<<$ trivial $>>$ dos mesmos ${ }^{27 ”}$, ou seja, para ele a trivialidade como sendo o elemento de limite ao quantum do dever, não corresponde ao melhor parâmetro.

Em que pesem as discussões sobre as características inerentes aos deveres fundamentais, o importante é saber que se trata de um campo ainda em conhecimento, onde não há verdades absolutas, mas, pelo contrário, inúmeras possibilidades, o que corrobora, conforme destacado acima, a necessidade do desenvolvimento do presente estudo a partir de uma perspectiva metodológica ínsita ao paradigma filosófico do múltiplo-dialético, conforme destacado já na introdução acima.

Objetivando uma das possibilidades, desdobradas dessa concepção múltipla, fundamento da racionalidade que conduz o presente estudo, o Grupo de Pesquisa Estado, Democracia Constitucional e Direitos Fundamentais, do Programa de Pós Graduação Stritu Sensu da Faculdade de Direito de Vitória, através de seus membros, entabulou um conceito para os Deveres Fundamentais, a fim de fixar um posicionamento acerca do tema, definindo dever fundamental como uma categoria jurídico-constitucional, fundada na solidariedade, que impóe condutas proporcionais àqueles submetidos a uma determinada ordem democrática, passíveis ou não de sanção, com a finalidade de promoção de direitos fundamentais ${ }^{28}$.

Não restam dúvidas, neste sentido, sobre a existência dos deveres fundamentais, bem como acerca de sua possível aproximação com os debates inerentes a perspectiva jurídico-filosófica da desobediência civil, como forma de contraposição popular frente a atos ou normas - neste trabalho - tomadas em um contexto de

\footnotetext{
${ }^{26}$ No original: "Deberes positivos general es son aquéllos cuyo contenido es una acción de assistência al prójimo que requiere un sacrifício trivial y cuya existencia no depende de la identidad del obligado ni de la del (o de los) destinatário (s) y tampoco es el resultado de algún tipo de relación contractual previa” (Tradução nossa).

${ }^{27}$ No original: “(...) el altruísmo mínimo, basado em la idea de sacrificio trivial, parece que no nos lo brinda. (...) si alguien tiene em su poder recursos sin título alguno - y a los cuales tiene direcho um tercero - debe entregarlos em su totalidad, no uma parte $<<$ trivial $>>$ de los mismos". (Tradução Nossa).

${ }^{28}$ Conceito construído coletivamente pelos membros do grupo de pesquisa Estado, Democracia Constitucional e Direitos Fundamentais, no $1^{\circ}$ semestre de 2013, coordenado pelos professores Dr. Daury Cesar Fabriz e Dr. Adriano Sant'Ana Pedra, do Programa de Pós-Graduação Stricto Sensu - Mestrado e Doutorado - em Direitos e Garantias Fundamentais da Faculdade de Direito de Vitória (FDV). Para maiores informações sobre as discussões de onde extraiu-se o conceito destacado acima, ver GONÇALVES, Luísa Cortat Simonetti e FABRIZ, Daury Cesar. Dever Fundamental: a construção de um conceito. In. DE
} 
baixíssima intensidade democrática, que torna governos, além de impopulares, ilegítimos para efetuação de reformas estruturais nos direitos fundamentais reconhecidos pela Constituição do Estado, tal como vem, nos últimos anos, ocorrendo no Brasil, conforme exemplo dado acima.

Portanto, os deveres fundamentais devem ser vistos como situações que se relacionam com matérias relevantes para a sociedade, cujos proveitos decorrentes de seu cumprimento extrapolarão os limites do individual, pois toda a coletividade será beneficiada, direta ou indiretamente, com o regular exercício desses deveres fundamentais, o que, via de consequência, acaba por fortalecer ou, em contextos de democracia de baixa ou baixíssima intensidade, até mesmo proteger - ainda mais - o Estado Democrático de Direito.

\section{INCONCLUSIVAS CONCLUSÕES ${ }^{29}:$ A DEMOCRACIA DE BAIXÍSSIMA INTENSIDADE ${ }^{30}, \quad A$ ILEGITIMIDADE DE UM GOVERNO E O DEVER FUNDAMENTAL DE DESOBEDIENCIA CIVIL}

Não é possível caminhar para elucidação das sínteses que se buscou fundamentar no movimento múltiplo dialético até aqui realizado, sem compreendermos melhor as premissas teórico-filosóficas que embasam a discussão posta acerca da democracia, sobretudo, do modelo democrático representativo de corte liberal e neoliberal.

Para tanto, se faz necessário reconhecer que a democracia assumiu papel central no campo político durante o século XX (SANTOS, 2016, p. 14) e que, em decorrência disso, talvez se tenha esquecido suas origens de luta, de diálogo, a ponto de não mais se discutir a democracia, passando-a a lugar comum, a local intocável, mesmo que seu corte liberal - e nas últimas décadas, neoliberal - tenha possibilitado um caminho de separação entre a sociedade civil e seus representantes (governo).

Sendo, diante do atual cenário, mais do que importante compreendermos a democracia como sendo resultado de um processo de muita luta, ou seja,

(...) a democracia não é uma dádiva, nem é assegurada. Ela exige conflito, a saber, o desafio corajoso da autoridade, a assunção de riscos e atos de coragem temerária, o testemunho

MARCO, Christian Magnus e OUTROS. Direitos Fundamentais Civis: teoria geral e mecanismos de efetividade no Brasil e na Espanha. Tomo I. Joaçaba: Editora UNOESC, 2013. p. 87-96.

${ }^{29}$ Essa expressão é emprestada de COUTO, Mia. E se Obama fosse Africano?. Artigo publicado no jornal Savana, Maputo. In.: E se Obama Fosse Africano?: e outras intervenções. São Paulo: Companhia das Letras, 2011, p. 197-202.

${ }^{30}$ Conforme se discutiu já neste trabalho e se discutirá abaixo, o que aqui chamamos de democracia de baixíssima intensidade, nada mais é do que uma derivação neoliberal da democracia representativa liberal, o que para Santos, pode ser percebido a partir da concepção de grau zero da democracia, ou seja, "(...) a democracia representativa liberal atingiu seu grau zero, minada por dentro por forças antidemocráticas, velhas e novas oligarquias com poder econômico para capturar o sistema político e o Estado e os pôr a serviço de seus interesses. Nunca como hoje se tornou tão evidente que vivemos em sociedades politicamente democráticas, mas socialmente fascistas" (2016, p. 107). 
ético, confrontações violentas e crises gerais em que se rompe a ordem político-social dada. $\mathrm{Na}$ Europa, a democracia não foi resultado da evolução natural ou da propriedade econômica. (...). Ela se desenvolveu porque uma grande quantidade de pessoas se organizaram coletivamente para reivindica-la (ELEY, 2006, p. 24).

Contudo, mesmo que seja necessário compreendermos a democracia, em suas origens fundantes, como um grande processo de lutas sociais conforme se percebeu acima, durante o último século, a democracia arrefeceu-se em seus fundamentos liberais, sendo que no último quarto do século passado, deu origem a um tipo novo de democracia, a democracia neoliberal ${ }^{31}$, ou seja,

A história da democracia ao longo do século XX foi em boa parte contada por aqueles que tinham um interesse, não necessariamente democrático, em promover certo tipo de democracia, a liberal, e inviabilizar ou, quando impossível, demonizar outros tipos de democracia. (...). A partir do fim da década de 1980, o pluralismo e a diversidade foram desaparecendo, e o debate, ou não debate, passou a centrar-se na democracia liberal, enquanto esta sub-repticiamente se transformava em algo bem distinto: a democracia neoliberal (SANTOS, 2016, p. 13).

De tais premissas, portanto, poderíamos concluir que se por um lado, a democracia liberal é de baixa intensidade, pois afasta da tomada de decisão, o real titular do poder que sustenta o Estado Moderno, de outro, a democracia neoliberal, por agravar, sobremaneira, tal contexto de afastamento, poderá ser compreendida como um modelo de baixíssima intensidade, “(...) uma vez que” ambas "se limita” (m) "a criar uma ilha de relações democráticas num arquipélago de despotismos (econômicos, sociais, raciais, sexuais, religiosos) que controlam efetivamente a vida dos cidadãos e das comunidades" (SANTOS, 2016, p. 80).

Assim, mesmo que o modelo de democracia de baixíssima intensidade esteja mergulhado em um série crise de legitimidade, não será simples abrirmos espaço para o surgimento de novos conceitos de política ou de democracia ${ }^{32}$, sobretudo em decorrência de termos compreendido, a partir do firmamento do Estado de Direito,

\footnotetext{
${ }^{31}$ Para melhor compreensão do motivo pelo qual Santos reconhece a democracia das últimas décadas do século passado, bem como a das primeiras décadas deste século, como sendo de corte neoliberal, é importante tracejar aquilo que esse autor entende como neoliberalismo, ou seja, "em um nível global, esse modelo econômico, social e político tem essas características: prioridade da lógica de mercado na regulação não só da economia como da sociedade em seu conjunto; privatização da economia e liberalização do comércio internacional; diabolização do Estado enquanto regulador da economia e promotor de políticas sociais; concentração da regulação econômica global em duas instituições multilaterais, ambas dominadas pelo capitalismo euro-norte-americano (o Banco Mundial e o Fundo Monetário Internacional), em detrimento das agências da ONU que antes supervisionavam a situação global; desregulamentação dos mercados financeiros; substituição da regulação econômica estatal (hard law) pela autorregulação controlada por empresas multinacionais (soft law)" (2016, p. 113). A partir dessas premissas, ao explicar os movimentos por detrás da democracia neoliberal, identificada no presente estudo, como uma modelo de democracia de baixíssima intensidade, Santos destacará que "(...) a democracia neoliberal dá total primazia ao mercado dos valores econômicos e, por isso, o mercado dos valores políticos tem de funcionar como se fosse um mercado de ativos econômicos. Ou seja, mesmo no domínio das ideologias e das convicções políticas, tudo se compra e tudo se vende. (...). Vivemos, pois, uma conjuntura perigosa, na qual foram desaparecendo ou sendo descaracterizados ao longo dos últimos cem anos os vários imaginários de emancipação social que as classes populares geraram com suas lutas contra a dominação capitalista, colonialista e patriarcal (2016, p. 22).

${ }^{2}$ Em relação a tais dificultadas, explica Santos que "apesar de evidente, essa crise sente dificuldade de abrir espaço para a emergência de novos conceitos de política e democracia. Essa dificuldade tem duas causas. Por um lado, o domínio das relações capitalistas, cuja reprodução exige hoje a coexistência entre a democracia de baixa intensidade e os fascismos sociais. Por outro lado,
} 
fruto do constitucionalismo moderno dos séculos XVII e XVIII, que a legitimidade de uma legislação, passou a ser vista a partir da legalidade que lhe fosse inerente, ou seja, subsumiu-se a legitimidade do poder do Estado, na ideia normalizadora de sua legalidade.

Um dos efeitos mais evidentes dessa subsunção do sentido de legitimidade à ideia da legalidade, está presente no fato de que a sociedade civil, o povo, sempre que o exercício institucional promova meios de retirada ou prejuízo a direitos fundamentais que lhes sejam inerentes, se distancie, cada vez mais, do cenário institucional de exercício da política.

Ao perceber que a legalidade, por si só, não é suficiente para a manutenção de um patamar jurídiconormativo capaz de emancipar, de libertar, grandes parcelas desse povo da miséria, da pobreza, da marginalização, um dos efeitos, é desacreditar não só nos políticos, seus representantes, nas instituições governamentais do Estado, mas também, na própria ideia de política.

Neste sentido, é necessário que se volte os olhos do povo para o debate sobre a legitimidade do poder que os governa, ou seja, a legitimidade de seus representantes para, contrariamente aos interesses da esmagadora maioria do povo brasileiro, por exemplo, aprovam legislações que depreciam ou, até mesmo, retiram direitos fundamentais desse povo.

Portanto, “(...) tanto os direitos como os deveres fundamentais integram o estatuto constitucional do indivíduo, ou melhor (...) da pessoa”, de modo que ao se falar de direitos e deveres fundamentais das pessoas, tais como, por exemplo, os direitos individuais ou os sociais, necessariamente, devemos lembrar da existência, concomitante, de deveres fundamentais necessários à essa concretização (NABAIS, 2007, p. 164).

O que, neste trabalho, dará ensejo a argumentação acerca da existência de um dever fundamental de desobediência civil em casos de práticas violadoras de direitos fundamentais, sejam eles individuais, sociais ou até mesmo meta-individuais, a partir de propostas de reformas estruturais do Estado, tomadas por um governo reconhecido como, num contexto de democracia de baixíssima intensidade, ilegítimo.

Este também é o entendimento de Peces-Barba Martínez, para quem

O exercício de um dever fundamental não traz benefícios exclusivamente ao titular do direito subjetivo correlato, quando existe, mas alcança uma dimensão de utilidade geral, beneficiando ao conjunto de cidadãos e a sua representação jurídica, o Estado ${ }^{33}$ (1987, p. 336 - tradução nossa).

Os deveres fundamentais, a desobediência civil e o reconhecimento de uma democracia de baixíssima intensidade, portanto, como se debateu neste trabalho, são contextos normativo-político-filosóficos que se inter-

a hegemonia da democracia liberal no imaginário social, muitas vezes por meio de recurso a supostas tradições ou memórias históricas que a legitimam" (2016, p. 82). 
relacionam, pois um dos mecanismos de proteção popular contra os desmandos de um governo ilegítimo, pode ser compreendida a partir do reconhecimento da existência de um dever fundamental de desobediência civil sempre que em um contexto de democracia de baixíssima intensidade, a ascensão de um governo ilegítimo, tente promover reformas estruturais em direitos fundamentais de todo um povo ${ }^{34}$.

Desse modo, é importante buscar no exercício cidadão da desobediência civil, meios para que o povo volte a figurar como pilar estruturante do modelo democrático, superando essa faze de afastamento das decisões de Estado, dando, inclusive, como nos chama atenção Santos (2016, p. 79, origem a uma nova concepção de democracia, qual seja

Levar a democracia a sério significa não só a levar muito além dos limites da democracia liberal, mas também criar um conceito de democracia novo: a democracia como todo o processo de transformação de relações de poder desigual em relações de autoridade partilhada.

A desobediência civil, portanto, surgirá como um caminho possível para se efetivar uma intensificação do exercício democrático do poder do povo que estrutura o governo do Estado, sobretudo em contextos de democracia liberal ou neoliberal, modelos estes de baixa ou baixíssima intensidade democrática, principalmente quando estão em debate reformas estruturais no Estado, tal como vem ocorrendo na atualidade dos brasileiros ${ }^{35}$, passíveis de comprometer direitos fundamentais, individuais, sociais e meta-individuais, das presentes e futuras gerações.

Seriam os atos de desobediência civil, nestes contextos de democracias de baixíssima intensidade, ao fim, verdadeiras ferramentas democráticas para o estabelecimento de uma democracia de alta intensidade, participativa, por onde decisões estruturantes acerca dos direitos fundamentais fossem tomadas às claras, com a

\footnotetext{
${ }^{33}$ No original: "El ejercicio de um dever fundamental no reporta beneficios exclusivamente al titular del derecho subjetivo correlativo, cuando existe, sino que alcanza una dimensión de utilidad general, beneficiando al conjunto de los ciudadanos y a su representación jurídica, el Estado".

${ }^{34}$ Sobre tal conclusão, é importante as palavras de Lipovetsky que, ao realizar uma análise do comportamento humano a partir de discussões sobre o meio ambiente que nos últimos anos desabrocharam por todo o mundo e com maior regularidade na segunda metade do século passado, chegou à conclusão de que "(...) a ideia de que a Terra está em perigo de morte, impôs uma nova dimensão de responsabilidade, uma concepção inédita das obrigações humanas que ultrapassa a ética tradicional, circunscrita às relações inter-humanas imediatas (1994, p. 244)", ou seja, o perigo pelo qual o presente modelo de sociedade nos inseriu, sobretudo a partir de um distanciamento da sociedade civil - povo - o de seus governantes, como fruto de uma democracia representativa de fundamento liberal, que se agrava e se torna ainda mais deletéria em contextos de crises institucionais como as enfrentadas pelo Brasil nos últimos anos, faz com que surja a necessidade de pensarmos em compreender a existência de uma nova dimensão de responsabilidade popular, a partir do reconhecimento de um dever fundamental de desobediência civil, em contextos de democracias de baixíssima intensidade, sempre que governos ilegítimos, nos termos destacados acima, tentem implementar reformas estruturais nos direitos fundamentais que são assegurados pela Constituição do país.

${ }^{35}$ São exemplos muito discutidos recentemente do contexto brasileiro as questões envolvendo o que se convencionou chamar de: Aumento de Tributos que impactaram, sobretudo, o preço dos Combustíveis em todo Território Nacional, a PEC do Teto dos Gastos Públicos; a Reforma Trabalhista; a Terceirização; a Reforma da Previdência; o Decreto Sobre a Reserva Nacional de Cobre e Associados (RENCA); o Decreto sobre Trabalho Escravo; as Privatizaçooes Rodoviárias e Aeroportuárias, bem como as Concessões para exploração de gás e petróleo para empresas internacionais, entre outras medidas que vem sendo tomadas pelo governo brasileiro e chanceladas - senão todas, sua grande maioria - pelo Congresso Nacional, desde 2014.
} 
maior participação popular possível, corroborando, assim, o enunciado constitucional que reconhece que todo o poder emana do povo.

\title{
FUNDAMENTAL DUTIES AND CIVIL DISOBEDIENCE IN LOW-INTENSITY DEMOCRACIES - APPROACHES AND DISTANCES FROM THE ILLEGITIMACY OF A GOVERNMENT
}

\begin{abstract}
The present reality of politics, especially how to do it after the world economic crisis in 2008, has brought peripheral countries, as well as some central ones, to an interesting debate about the unfolding of the (neo) liberal model of representative democracy (low / low intensity democracy), in relation to the removal of civil society from its rulers, especially in contexts where such a departure prompts the emergence of governments and illegitimate representatives who seek, in the midst of the troubled scenario, to implement structural reforms in their which, as will be discussed in this study, may lead to the possible existence of a fundamental duty to civilly disobey the laws or political acts emanating from these governments, based on the analysis of the right of resistance and its characterization process in civil disobedience. illegitimate, fruits of these troubled scenarios of economic, institutional and political crisis. ica.
\end{abstract}

Palavras-chave: Deveres Fundamentais; Desobediência Civil; Democracia de Baixíssima Intensidade; Ilegitimidade; Governo.

\section{REFERENCIAS}

ARENDT, Hannah. A Desobediência Civil. Brasília: UNB, 1988.

BAYÓN, Juan Carlos. Los Deberes Positivos Generales y la Determinación de Sus Límites: observaciones al artículo de Ernesto Garzón Valdés. In: DOXA 3, 1986.p.35-54. 
BOÉTIE, Etienne de La. Discurso da Servidão Voluntária. Trad. J. Cretella Jr. e Agnes Cretella. São Paulo: Revista dos Tribunais, 2003.

CAMPANHA, Breno Maifrede. Liberdade para Desobedecer e Desobediência para Libertar. In.: Conselho Nacional de Pesquisa e Pós-Graduação em Direito (CONPEDI) (org.). Direitos Fundamentais e Democracia II. Florianópolis: FUNJAB, 2012.p. 316-342. Disponível em: <http://www.publicadireito.com.br/publicacao/livro. php?gt=124>. Acessado em 11 de Setembro de 2017.

COHEN, Jean C.; ARATO, Andrew. Civil Society and Political Theory. EUA: Massachusetts Institute of Technology, 1997.

COSTA, Nelson Nery. Teoria e Realidade da Desobediência Civil. Rio de Janeiro: Forense, 1990.

COUTO, Mia. E se Obama fosse Africano?. Artigo publicado no jornal Savana, Maputo. In.: E se Obama Fosse Africano?: e outras intervenções. São Paulo: Companhia das Letras, 2011, p. 197-202.

ELEY, Geoff. Forjando a Democracia - a história da esquerda na Europa, 1850-2000. Trad. por CASTANHEIRA, Paulo César. São Paulo: Editora Fundação Perseu Abramo, 2005.

GARCIA, Maria. Desobediência Civil - Direito Fundamental. 2ed. rev. atual. e ampl. São Paulo: Editora Revista dos Tribunais, 2004.

GONÇALVES, Luísa Cortat Simonetti e FABRIZ, Daury Cesar. Dever Fundamental: a construção de um conceito. In. DE MARCO, Christian Magnus e OUTROS. Direitos Fundamentais Civis: teoria geral e mecanismos de efetividade no Brasil e na Espanha. Tomo I. Joaçaba: Editora UNOESC, 2013.

KROHLING, Aloísio. Dialética e Direitos Humanos - múltiplo dialético: da Grécia à Contemporaneidade. Curitiba: Juruá Editora, 2014.

LAFER, Celso. A Reconstrução dos Direitos Humanos; um diálogo com o pensamento de Hannah Arendt. São Paulo : Companhia das Letras, 1988 . 
LLÓRENTE, Francisco Rubio. Los Deberes Constitucionales. In: Revista Española de Derecho Constitucional. Año 21. Núm. 62. Mayo-Agosto 2001.p. 11-56.

LUCAS, Doglas Cesar. Direito de Resistência e Desobediência Civil: Histórias e Justificativas. In.: Revista Direito em Debate, Vol. 8, N. 13, 1999, p. 23-53. Disponível em: <https://www.revistas.unijui.edu.br/index.php/revistadireitoemdebate/ article/view/ 807/525>. Acessado em 11 de Agosto de 2017.

MARASCHIN, Claudio e BRUSCATO, Giovani Tavares. A Teoria e a Prática da Desobediência Civil: um estudo a partir da doutrina contemporânea. In.: Revista do Curso de Direito da FSG. Ano 5, N. 9, jan/jun., p. 5567, 2011. Disponível em: <http://ojs.fsg.br/index.php/direito/article/view/734>. Acessado em 17 de Setembro de 2017.

NABAIS, José Casalta. Por uma liberdade com responsabilidade: estudos sobre direitos e deveres fundamentais. Coimbra: Coimbra Editora, 2007.

PAUPÉRIO, Arthur Machado. Teoria Democrática da Resistência. 3.ed. Rio de Janeiro: Forense Universitária, 1997.

PECES-BARBA MARTÍNEZ, Gregorio. Los deberes fundamentales. Doxa. Alicante, n. 04, p. 329-341, 1987. Disponível em: <http://bib.cervantesvirtual.com/servlet/Sirve Obras/12837218659036051876657/cu aderno4/Doxa4_19.pdf >.Acesso em: 15 ago. 2014.

PINTO, Alessandro Nepomuceno. A Desobediência Civil e o Movimento dos Sem-Terra (MST). In.: VARELLA, Marcele Dias (org.). Revoluções no Campo Jurídico. Joinville: Oficina, 1998. p. 55-91.

RAWLS, John. Uma Teoria da Justiça. 3ed. São Paulo: Martins Fontes, 2008.

REPOLÊS, Maria Fernanda Salcedo. Habermas e a desobediência civil. Belo Horizonte: Mandamentos, 2003.

SANTOS, Boaventura de Sousa. A Difícil Democracia - reinventar as esquerdas. São Paulo: Boitempo, 2016.

SILVA, Heleno Florindo da e FABRIZ, Daury Cesar. O MEIO AMBIENTE NATURAL E A PROTEÇÃO 
INTEGRAL DAS CRIANÇAS: a Educação Ambiental como Dever Fundamental dos Pais para a Preservação das Presente e Futuras Gerações. In.: Revista do Programa de Pós-Graduação em Direito da UFC. Vol. 35, n. 2, 2015, p. 181-200.

THOREAU, Henry David. A desobediência civil. Tradução: Sérgio Karam. Porto Alegre: L\&PM, 1997.

VALDÉS, Ernesto Garzón. Los Deberes Positivos Generales y su Fundamentación. In: DOXA3, 1986a. p. 17-33.

Algunos Comentarios Críticos a Las Críticas de Juan Carlos Bayón y Francisco Laporta. In: DOXA 3, 1986b.p. $65-68$

WALZER, Michael. Das obrigações políticas. Rio de Janeiro: Zahar, 1997.

Trabalho enviado em 13 de abril de 2018

Aceito em 05 de julho de 2018 